\title{
УДК 633.111.1:631.52:575.1 \\ https://doi.org/10.53040/gppb7.2021.42 \\ USING INSENSITIVE PPD-D1a ALLELE FOR THE EARLY FORMS SELECTION OF BREAD WHEAT IN THE INITIAL SELECTION STAGES
}

\author{
Mirskaya G.V., Rushina N.A., Sinyavina N.G., Kochetov A.A., Chesnokov Yu.V. \\ Agrophysical Research Institute, Saint-Petersburg, Russia \\ e-mail: galinanm@gmail.com
}

\begin{abstract}
Determination the photoperiod-insensitive allele $(P p d-D 1 a)$ in wheat cultivars is necessary for use in breeding development of newly wheat cultivars. The aim of our study was to select breeding material by screening $P p d-D 1$ gene alleles and estimation value and the degree of heterosis in $\mathrm{F}_{1}$. Using these two methods, it is possible to select genetic material for increased breeding of new wheat lines that combine earliness and increased productivity. In this study 26 varieties of spring soft wheat were screened for the Ppd-D1 gene alleles. The Ppd-Dla allele was detected in 12 wheat varieties (ITMI 10, 29, 47, 57, 58, 59, 60, 89, 94, AFI-91, AFI-177, Opata 85), the recessive Ppd-Dlb allele was detected in 14 wheat varieties (ITMI 7, 31, 32, 44, 80, 88, 83, 115, Zlata, Lisa, Agata, Lubava, W7984). Based on the results of a comprehensive assessment, parental pairs were chosen and 10 recombinants were obtained. Based on estimation value and the degree of heterosis of the main ear traits in $F_{1}$, such as "ear length", "number of grains from the ear" and "weight of grains from the ear" were identified 4 crosses as initial to create wheat cultivars that combine earliness and increased productivity.

Key words: spring bread wheat, photoperiod, molecular markers, heading time, hybrid, heterosis, spike productivity.

Введение

С целью более быстрого создания раннеспелых сортов яровой пшеницы необходим целенаправленный подбор родительских форм - доноров скороспелости, который возможен только при использовании современных методов молекулярной селекции. Для идентификации генотипов с доминантными или рецессивными аллелями гена $P p d-D 1$ разработаны аллель-специфичные праймеры [1]. Установлено, что сорта пшеницы, имеющие доминантный аллель гена Ppd-Dla, достоверно опережают другие генотипы по скорости развития до колошения и являются более скороспелыми даже при возделывании в условиях длинного светового дня. Не менее важным является преодоление отрицательной корреляции между скороспелостью и продуктивностью. В связи с этим, целью нашей работы является анализ возможности создания рекомбинантов пшеницы сочетающих высокую скорость развития и продуктивность методом молекулярно-генетического скрининга и на основе оценки величины и степени проявления гетерозиса в $\mathrm{F}_{1}$.
\end{abstract}

\section{Материалы и методы}

В качестве материала для исследований использовали сорта яровой мягкой пшеницы (Triticum aestivum L.) Агата, Любава, Злата, Лиза, Opata 85, авторские ультраскороспелые линии AFI-177, AFI-91, синтетический гексаплоид: W7984(Synthetik) и 18 рекомбинантных инбредных линий (РИЛ) картирующей популяции ITMI (International Triticeae Mapping Initiative). РИЛ популяции ITMI отличаются полиморфизмом по большинству хозяйственно-ценных признаков.

Выращивание и оценку образцов мягкой пшеницы, а также гибридов первого поколения проводили в условиях регулируемой агроэкосистемы биополигона ФГБНУ «Агрофизический научноисследовательский институт» (АФИ) в вегетационных облучательных установках (ВОУ), оснащенных лампами ДНаТ-400 с заданной облученностью $50 \pm 0.5$ Вт/м² ФАР. Фотопериодический режим включал 16-ти часовое ежесуточное освещение. Температурный режим поддерживался на уровне $23-24^{\circ} \mathrm{C}-$ день/ $19-20^{\circ} \mathrm{C}$ ночь. Повторность для каждого сорта и линии - 15-кратная, для гибридов $\mathrm{F}_{1}$ - 5кратная. Образцы были проанализированы по ряду хозяйственно-ценных признаков: длительность периода «всходы-колошение», длина колоса, число зерен в колосе, масса зерна с колоса. Показатель наследования изучаемых признаков рассчитывали по методике [2] по формуле: $\boldsymbol{H}=\frac{\boldsymbol{F}-\boldsymbol{P}_{c p}}{\boldsymbol{P}_{л}-\boldsymbol{P}_{c p}}$, где 
$\mathrm{F}$ - символ среднего значения признака и гибрида; $\mathrm{P}_{\mathrm{cp}}$ - среднее значение признаков родителей; $\mathrm{P}_{л}-$ среднее значение признака лучшего родителя.

Для проведения молекулярно-генетического скрининга изучаемых образцов геномную ДНК выделяли из 5-дневных проростков растений по стандартной методике с использованием СТАВ-буфера. Для выявления генотипов с доминантным и рецессивным аллелями гена $P p d-D 1$ использовали опубликованный протокол и аллель-специфичные праймеры [3].

\section{Результаты и обсуждение}

В результате проведенного молекулярно-генетического анализа 26 линий и сортов яровой мягкой пшеницы доминантная аллель Ppd-D1а обнаружена у 12 образцов (ITMI 10, 29, 47, 57, 58, 59, 60, 89, 94, AFI-91, AFI-177, Opata 85) (рис.1).

Среди изученного в данном эксперименте сортимента пшеницы носители доминантного аллеля $P p d-D l a$ составили $46 \%$ и в основном они представлены генотипами. В тоже время, все включенные в анализ сорта отечественной селекции являются носителями рецессивного аллеля гена $P p d-D 1 b$ определяющего высокую фоточувствительность. Показано, что частота встречаемости доминантного аллеля Ppd-Dla среди сортов мягкой пшеницы, возделываемых на территории РФ крайне мала (до 8,5\%) [4]. В тоже время отмечается все большее распространение аллеля Ppd-Dla в современных коммерческих сортах мягкой пшеницы по всему миру [5]. Для идентификации генотипов со слабой и сильной фотопериодической чувствительностью классическими методами требуется большой объем выборки и длительный период культивирования растительного материала. Поэтому, использование молекулярных маркеров, сцепленных с целевыми локусами гена $P p d-D 1$ на этапе оценки исходного материала и подбора родительских пар для гибридизации, позволит значительно ускорить процесс введения в современные сорта пшеницы Ppd-Dla аллель слабой фотопериодической чувствительности.

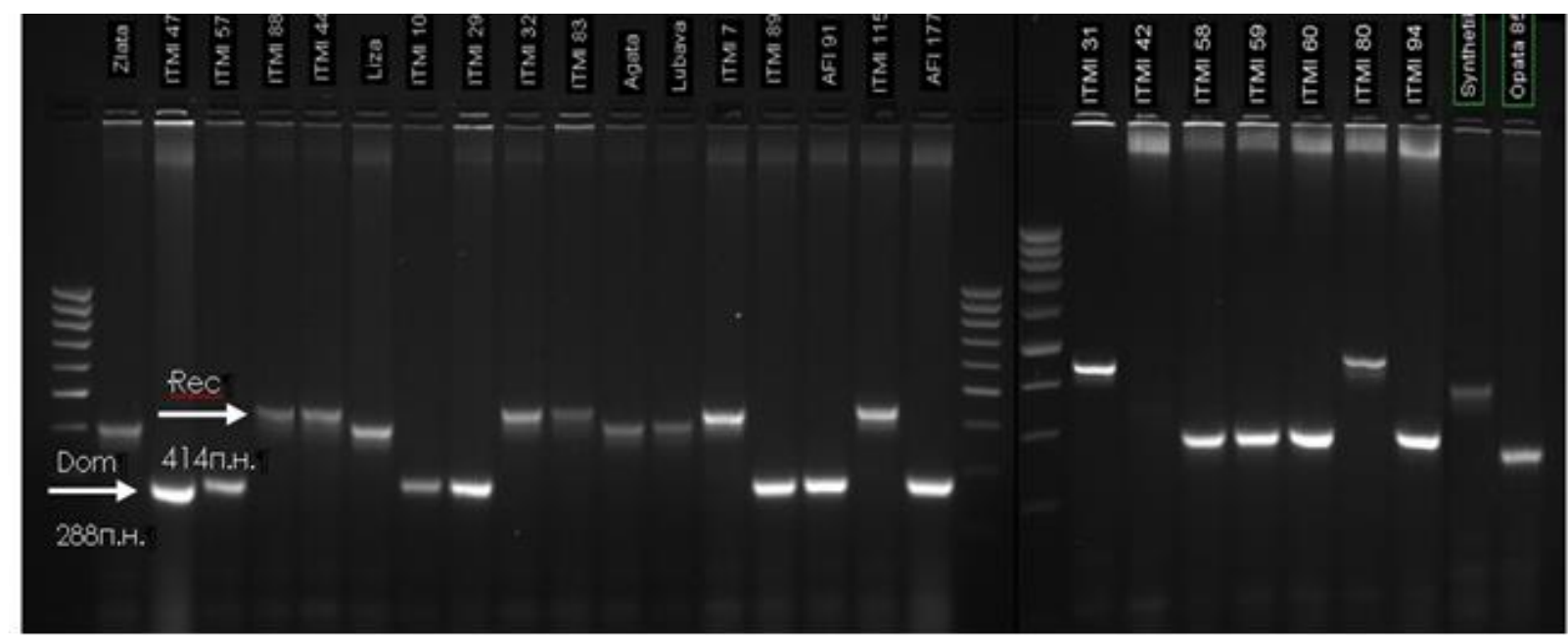

Рисунок 1. Фрагмент электрофореграммы скрининга исходных сортов и линий пшеницы по аллелям гена Ppd-D1 с помощью аллель-специфичных праймеров (доминантный аллель - 288 п.н., рецессивный аллель - 414 п.н.)

Одними из основных элементов продуктивности, из которых слагается урожайность, являются показатели продуктивности главного колоса: длина колоса, число зерен с колоса и масса зерна колоса. Проведенный нами морфо-биологический скрининг выявил разнообразие в проявлении этих признаков и их сочетаник среди исследованных сортов и линий мягкой пшеницы. По признаку «длина колоса» проанализированные растения входили в группу со средним и длинным колосом, значения признака находились в пределах 6,6 cм (AFI-91) - 12.3 см (Любава). Значения показателя озерненности главного колоса варьировали от 16,5 шт. (ITMI 59) до 38,9 шт. (Лиза). Масса зерна колоса - один из наиболее важных элементов структуры урожая пшеницы на ранних этапах селекционного процесса, так как селекционеры осуществляют индивидуальный отбор нового селекционного материала по колосу. В ходе проведенного анализа по признаку «масса зерен с колоса» выявлено, что исследуемые образцы входят в группу с малым (до 1.4 г) и средним (до 1.9) показателем массы зерна. Масса зерна колоса варьировала от 0.8 г до 1.9 г. В целом наибольшую массу зерна колоса формировали образцы ITMI 80, ITMI 115, caмой низкой массой зерна колоса характеризовались образцы ITMI 31, ITMI 59. 
Известно, что характер наследования признаков в $\mathrm{F}_{1}$ может служить предварительным показателем ценности комбинации. Наличие гетерозиса по числу и массе зерен с колоса является одним из условий, при которых возникают трансгрессии по продуктивности. В комбинациях с гетерозисом по продуктивности в $\mathrm{F}_{1}$ примерно у 85\% проявляются трансгрессии по продуктивности, при промежуточном наследовании - у 15-25\% [6]. Оценка возможности создания рекомбинантов, сочетающих высокую скорость развития до колошения и повышенную продуктивность колоса, проведена на гибридах $\mathrm{F}_{1}$ 10-ти комбинаций скрещивания. Полученные данные (таблица 1) свидетельствуют, что гетерозис отмечается по всем показателям продуктивности колоса в зависимости от родительских пар, включенных в скрещивания. В комбинациях скрещивания ITMI 7 х AFI-177, AFI-91 x ITMI 7 выявлен гетерозис по всем исследуемым признакам. Гетерозис по числу зерен с колоса и массе зерна с колоса был отмечен в комбинациях скрещивания Любава х ITMI 88 и ITMI 89 x AFI-91. Гетерозис только по массе зерна с колоса отмечен у Любава х ITMI 10.

Таблица 1. Распределение гибридов $\mathrm{F}_{1}$ по характеру наследования признаков продуктивности колоса*

\begin{tabular}{|c|c|c|c|}
\hline Гибрид & Длина колоса, см & Число зерен с колоса, шт & Масса зерен с колоса, г \\
\hline Любава х ITMI 88 & 0.85 УЛР & $2.02 \Gamma$ & $3.29 \Gamma$ \\
\hline Любава х ITMI 10 & 0.42 УЛР & 1.38 ДЛР & $3.00 \Gamma$ \\
\hline Любава х ITMI 57 & -0.30 УХР & -122.00 Д & -1.36 ДХР \\
\hline Агата х ITMI 29 & 0.68 УЛР & 0.81 УЛР & 1.40 ДЛР \\
\hline Любава х ITMI 47 & -0.09 УХР & -0.66 УХР & -0.33 УХР \\
\hline Агата х ITMI 88 & 1.11 ДЛР & 0.77 УЛР & 0.89 УЛР \\
\hline ITМІ 7 x АФИ 177 & $4.43 \Gamma$ & $15.11 \Gamma$ & $6.33 \Gamma$ \\
\hline АФИ 91 x ITMI 7 & $3.43 \Gamma$ & $31.00 \Gamma$ & $6.00 \Gamma$ \\
\hline ITMI 89 x АФИ 91 & 1.42 ДЛР & $4.71 \Gamma$ & $2.43 \Gamma$ \\
\hline
\end{tabular}

* >-2 - депрессия (Д), -1- -2 - доминирование худших родителей (ДХР), 0 - -1 - уклонение в сторону худших родителей (УХР), 0 - соответствие признаков у родителей и гибридов, $0-+1-$ уклонение в сторону лучших родителей(УЛР), $+1-+2-$ доминирование лучших родителей (ДЛР), >+2- гетерозис (Г).

\section{Выводы}

Таким образом, в результате проведенного молекулярно-генетического скрининга с аллельспецифичными праймерами гена $P p d-D 1$ доминантный аллель $P p d-D 1 a$ обнаружен у 12 образцов яровой мягкой пшеницы, 14 форм характеризовались наличием рецессивного аллеля $P p d-D 1 b$. Изучен характер наследования основных признаков продуктивности в первом гибридном поколении, выявлены комбинации скрещивания с проявлением гетерозиса по длине колоса, числу и массе зерна с колоса. Определены комбинации скрещивания перспективные для создания линий пшеницы, сочетающих высокую скорость развития и повышенную продуктивность колоса - Любава х ITMI 88, ITMI 7 x АФИ 177, АФИ 91 x ITMI 7, ITMI 89 x АФИ 91.

\section{Литература}

1. YANG, F.P., ZHANG, X.K., XIA, X.C., LAURIE, D.A., YANG, W.X., HE, Z.H. Distribution of the photoperiod insensitive Ppd-Dla allele in Chinese wheat cultivars. // Euphytica. 2009. V.165. P. 445-483.

2. PETR, F.C., FREY, K.J. Genotypic correlations, dominance and heritability of quantitative characters in oats. // Crop Science. 1966. V.6. P.259-262.

3. BEALES, J., TURNER, A., GRIFFITHS, S. et al. A pseudo-response regulator is misexpressed in the photoperiod insensitive Ppd-Dla mutant of wheat (Triticum aestivum L.) // Theor. Appl. Genet. 2007. V.115. No 5. P. 721-733.

4. ЛИХЕНКО, И.Е., СТАСЮК, А.И., ЩЕРБАНЬ, А.Б., ЗЫРЯНОВА, А.Ф., ЛИХЕНКО, Н.И., САЛИНА, Е.А. Изучение аллельного состава генов $V r n-1$ и $P p d-1$ у раннеспелых и среднеранних сортов яровой мягкой пшеницы Сибири// Вавил.журнал ген.и сел. 2014. Т.18. №4. С.691-703.

5. KISS, T., BALLA, K.,VEISZ, O., LANG, L., BEDO, Z., GRIFFITHS, S., ISAAC, P., KARSAI, I. Allele frequencies in the $V R N-A 1, V R N-B 1$ and $V R N-D 1$ vernalization response and $P P D-B 1$ and $P P D-D 1$ photoperiod sensitivity genes, and their effects on heading in a diverse set of wheat cultivars (Triticum aestivum L.). // Mol. Breeding. 2014. V.34. P.297-310.

6. ФОМЕНКО, М.А., ГРАБОВЕЦ, А.И. Трансгрессивная изменчивость и селекция на продуктивность у озимой мягкой пшеницы на Дону // Зерновое хозяйство России. 2013. № 1. С. 34-39. 